\title{
Gastrointestinal response to food W13-W19
}

W13

EFFECTS OF FERMENTABLE DIETARY FIBRE ON CELL PROLIFERATION, MORPHOMETRY AND CRYPT BRANCHING IN THE COLONIC EPITHELIUM.

McCullough JS, Carr KE, B Ratcliffe ${ }^{1}, \mathrm{~N} \mathrm{Mandir}^{2}$ \& Goodlad RA ${ }^{2}$. The Queens University of Belfast, Anatomy Dept, Medical Biology Centre, Belfast.

'The Robert Gordon University, Kepplestone, Aberdeen.

2Imperial Cancer Research Fund, Histopathology Unit, 35-43 Lincoln's Inn Fields, London WC2A 3PN.

Conventional and germ-free rats were fed a fibre-free diet with or without the addition of a mixture of fermentable dietary fibres. Intestinal epithelial crypt cell production rates in the colon were dramatically increased by fibre, but only in the conventional group, suggesting that it is the breakdown of fibre by the colonic microflora that is responsible for its proliferative actions in the hind gut.

Morphometrical analysis demonstrated that fibre also had direct effects on the number of crypts per circumference, and the number of goblet cells per crypt in the colon. The total number of goblet cells was also influenced by the presence of bacteria. Significant effects of fibre and bacteria on muscle nuclei were also observed, suggesting a direct effect of fibre on muscle mass.

There was a large increase in the number of branched crypts (Cryp Branching Index) in the mid colon of the germ free rats (32.4\% \pm 9.5 vs $7.6 \pm 1.7 ; \quad P<0.001$ (mean $\pm S E M n=15)$ ), with little effect of fibre being observed.

Crypt branching can lead to the production of new crypts -if they go on to fission, and this may be mediated by the disregulation of cell adhesion. Crypt branching may thus be an important process in the development of, or clonal expansion of, carcinogenesis. However the large number of branched crypts seen in the germ-free rats suggests that not all crypts have to undergo crypt fission, and that crypt branching does not necessarily equate with crypt fission.

\section{THE COLONIC EFFECTS OF BRAN-LIKE PLASTIC PARTICLES: IS DIETARY FIBRE "ROUGHAGE" AFTER ALL?}

SJ Lewis, KW Heaton; Department of Medicine, Bristol Royal Infirmary. Bristol, BS2 8HW England.

INTRODUCTION The mechanisms by which dietary fibre exerts its laxative action are not fully understood. Studies using sliced plastic tubing showed a decrease in bowel transit times. But their relevance can be questioned due to the unphysiological form of the plastic and its potential to leak out plasticisers. We set out to study the effect of plastic particles similar in size and shape to wheat bran and devoid of plasticisers.

METHODS In a crossover design, 29 volunteers were asked to take coarse raw bran and plastic particles (shredded PTFE sheeting $0.15 \mathrm{~mm}$ thick, both the bran and plastic were sieved to be $1.43 \mathrm{~mm}$ in diameter) for 9 days with a 2 week wash out period. They took as much bran as they could tolerate (27.1g/day SD 8.4). After at least 2 weeks they took plastic particles (24g/day). Before and during each study period whole gut transit time (WGTT) was measured and a 4 day dietary record was completed. Stool pH and B-glucuronidase activity were measured.

RESULTS Dietary intake did not change with either supplement. Baseline WGTT, interdefecatory intervals (IDI), stool form, output (o/day) and B-glucuronidase were similar before both wheat bran and plastic consumption. There was a decrease in faecal B-glucuronidase activity, WGTT and IDI with wheat bran and plastic particles. Stool form score and median stool output increased for both groups. Stool pH decreased while taking the plastic, but not with bran.

\begin{tabular}{llllll}
\multicolumn{5}{c}{ Parameters before and after supplement (mean. SD or median. 10 range) } \\
\multicolumn{5}{c}{ Wheat bran } & \multicolumn{2}{c}{ Plastic } \\
Baseline & Active & Baseline & Active \\
Stool form & $3.72(0.96)$ & $4.60(1.03)^{*}$ & $3.72(0.58)$ & $4.46(1.00)^{*}$ \\
log B-gluc^ & $1.60(0.29)$ & $1.47(0.24)^{*}$ & $1.64(0.18)$ & $1.44(0.23) *$ \\
WGTT (h) & $60(42,73)$ & $37(30,62)^{*}$ & $57(41,67)$ & $35(29,49)^{*}$ \\
IDI (h) & $24(15,24)$ & $18(12,24)^{*}$ & $24(24,24)$ & $18(12,24)^{*}$ \\
Stool output & $124(79,174)$ & $188(90,298)^{*}$ & $115(72,178) 234(120,284)^{*}$ \\
& & & &
\end{tabular}

$\log _{10}$ B-glucuronidase activity $(\mathrm{mmol} / \mathrm{g} / \mathrm{h}) \quad * \mathrm{p}<0.05$

DISCUSSION Plastic particles produced a similar reduction in WGTT as wheat bran. Changes in IDI, stool form, weight and output reflected the reduction in intestinal transit time. Overall, plastic 'pseudobran' altered colonic function at least as much as bran.
NUTRIENT REGULATION OF THE DI/TRIPEPTIDE TRANSPORTER, hPepT1, IN Caco-2 CELLS

Dianne Walker, David T. Thwaites, Nicholas L. Simmons, Harry J. Gilbert* \& Barry H. Hirst. Depts.of Physiological Sciences and *Biological \& Nutritional Sciences, University of Newcastle upon Tyne.

Absorption of small peptides, substrates for the cloned intestinal di/tripeptide transporter, hPepTl, accounts for a significant proportion of total dietary protein uptake. Regulation of $\mathrm{hPepTl}$ is, therefore, important nutritionally. This study reports regulation of $\mathrm{hPepT} 1$ in response to the nutrient substrate glycyl-L-glutamine (Gly-Gln) in the human intestinal cell line, Caco-2.

Northern blots of Caco-2 poly-(A)+ RNA probed with a [32P]labelled 600 bp 5' EcoRI fragment of hPepT1 cDNA indicated a 2-3 fold increase in signal intensity $(n=3)$, when corrected against $\beta$-actin, for cells grown in medium supplemented at three days post-confluence with Gly-Gin as compared with controls. One blot probed with cDNA to sucrase-isomaltase, an intestinal brush border enzyme, showed no increase in signal intensity as a result of Gly-Gln exposure, suggesting that $\mathrm{hPepT} 1$ is selectively regulated in response to Gly-Gln.

A corresponding functional increase in hPepTl transport activity was also measured in Gly-Gln-supplemented Caco-2 cells. $V_{\max }$ for apical uptake of $\left[{ }^{14} \mathrm{C}\right]$ glycyl- $\left[{ }^{14} \mathrm{C}\right]$ sarcosine in sodium-free conditions (apical $\mathrm{pH} 5.5$, basolateral $\mathrm{pH} 7.4$ ) increased from $14.5 \pm 1.0$ to $23.8 \pm 3.3$ nmol.cm-2. $(5 \mathrm{~min})^{-1}$ (mean \pm S.E.M., $\left.\mathrm{n}=4\right)$.

The half-life of $\mathrm{hPepT} 1 \mathrm{mRNA}$, as determined by the reduction in signal intensity from poly-(A) ${ }^{+}$RNA prepared from Caco-2 cells grown over 48 hours in the presence of actinomycin D to stop RNA transcription, was slightly increased by Gly-Gln supplementation of the medium $\left(t_{1 / 2}=37 \pm 15 \mathrm{hrs}, \mathrm{n}=3\right)$ compared to control $\left(\mathrm{t}_{1 / 2}=26 \pm 9\right.$ hrs, $n=3$ ).

We conclude that small intestinal di/tripeptide transporter activity is able to adapt to changes in nutrient supply and that an element of this adaptation occurs at the level of mRNA stability.

\section{ROLE OF DIETARY POLYAMINES IN GROWTH}

S. Bardocz, G. Grant, D.S. Brown, T.J. Duguid, A. Ralph and A. Pusztai

The Rowett Research Institute, Bucksburn, Aberdeen AB2 9SB, Scotland, UK

The importance of extracelluar polyamines during adaptational growth of the small intestine is widely recognised.

However, the role of the diet as a source of polyamines for supporting growth generally has been totally neglected. In our laboratory different types of food (fruits, vegetables, meat and milk products) have been analyzed by HPLC to determine their polyamine (putrescine, spermidine and spermine) content. Without exception, all foodstuffs contained polyamines although the concentrations varied across the different individual food components.

By using ${ }^{14} \mathrm{C}$-labelled putrescine, spermidine and spermine, we found that polyamines are readily taken up by the gut and enter the systemic circulation. Food therefore appears to constitute the main natural source of polyamines for man and animals.

Although the enzymes diamine- and polyamine oxidase limit the bioavailability of the natural polyamines, most of the dietary spermidine and spermine and about $20-30 \%$ of the putrescine is available for uptake.

The distribution of polyamines in the body, as determined by measuring the accumulation of ${ }^{14} \mathrm{C}$-spermidine in different tissues of the rat, correlated with the metabolic activity and growth of particular organs. Thus, phytohaemagglutinin did not only induce extensive hyperplastic growth of the gut but also stimulated the preferential accumulation of labelled spermidine in this tissue. Correspondingly, when skeletal muscle growth was promoted by the B-agonist, clenbuterol, ${ }^{14} \mathrm{C}$-spermidine was sequestered by the hind leg gastrocnemius muscle.

It is concluded that food polyamines are not only necessary for normal body metabolism but are also used and directed preferentially to tissues and organs which have been stimulated to grow by metabolic signals. 
EARLY COORDINATED EXPRESSION OF A SODIUM GLUCOSE LINKED TRANSPORTER (SGLT1) AND GLUCOSE TRANSPORT IN HUMAN JEJUNAL VILLUS-ATTACHED ENTEROCYTES DK O'Riordan, A Turvey \& MW Smith. Department of Physiology, Royal Free Hospital School of Medicine, London NW3 2PF (introduced by JRF Walters).

Rat jejunal enterocytes only express SGLT1 and glucose transport during migration over the upper part of the villus'. Cells migrating out of human crypts are, however, older than in rats $(24 \mathrm{~h}$ and $9 \mathrm{~h}$ respectively) and this may affect the profile of transport expression. Aim : To test if differences in cell age alter the villus location of SGLT1 expression and glucose transport and determine whether the correlation between these two parameters is similar in humans and rats. Methods : Eight jejunal biopsies obtained from patients with no macroscopic or microscopic small bowel disease were incubated for 1 $\min$ in $4 \mathrm{mM}\left[{ }^{3} \mathrm{H}\right]$ glucose before being freeze dried and embedded in araldite. Serial sections were then used to measure glucose transport by autoradiography and SGLT1 by immunocytochemistry. The villus location of glucose transport and SGLT1 was later determined by microdensitometry in arbitrary absorbance units

Results: Glucose transport already present in cells leaving the crypt increased linearly during migration to the mid-villus (glucose uptake 4.8 \pm 1.4 at the villus base; $95 \pm 2.5$ at the mid-villus; $r=0.99 ; p<$ $0.001)$. SGLT1 expression was also apparent in basal villus enterocytes. SGLT1 protein then increased linearly during cell migration to the midvillus ( $24.57 \pm 1.82$ at the crypt/villus junction ; $42 \pm 2$ at the midvillus; $r=0.94 ; p<0.001$ ). No further increase in SGLT1 or glucose transport occured in the upper villus.

Conclusion :Glucose transport correlates with SGLT1 expression in humans and rats. The initial expression of SGLTl and glucose transport occur closer to the crypt/villus junction in human villi. The age of cells beginning to express SGLT1 and glucose transport are, however similar (24 and $20 \mathrm{~h}$ for human and rat cells). This suggests temporal control over cell differentiation.

1. Debnam et al. (1995). Eur. J. Physiol, 430, 151-159.

\section{INDUCTION OF APOPTOSIS AND SUPPRESSION OF} ABERRANT CRYPT FOCI IN THE COLONIC MUCOSA OF RATS FED THE GLUCOSINOLATE SINIGRIN.

T Smith, SRR Musk and IT Johnson.

Institute of Food Research - Norwich Laboratory, Norwich Research Park, NORWICH, NR4 7UA.

Glucosinolates are the parent compounds of isothiocyanates (ICs) found in many cruciferous vegetables. The ICs are released by enzymes of the plant tissue or the colonic microflora, and are known to protect against chemically induced carcinogenesis by modulating Phase $I$ and Phase II carcinogen metabolism. However in previous work we have shown that ICs are also selectively toxic to human tumour cells (HT29). In this study we examined the effect of the glucosinolate sinigrin on crypt cytokinetics and induction of aberrant crypt foci (ACF). Sinigrin was given only after treatment with the chemical carcinogen DMH.

Methods: Three groups of 20 male Wistar rats were fed a basal semisynthetic diet. Two groups were given DMH (ca $30 \mathrm{mg} / \mathrm{Kg}$; s/c injection) after 1d and again after 5d, and after 24h one of these groups was given sinigrin $(400 \mu \mathrm{g} / \mathrm{g}$ diet). Ten rats from each group were killed $2 \mathrm{~d}$ after the final treatment with DMH for assessment of cytokinetics.

The remaining rats were killed after 6 weeks for assessment of ACF.

Whole mucosa was fixed in acetic acid ethanol (25:75) and bulk-stained

in Feulgen's reagent. The numbers and positions of mitotic and apoptotic nuclei in whole crypt mounts were assessed by light

microscopy. The total numbers of aberrant crypt foci were estimated by inspection of whole mucosal sheets under low power microscopy. The significance of differences in the numbers of ACF between groups was assessed by two-way ANOVA with body weight as a covariate.

Results: After 2d, DMH-treated rats had increased proliferation in the upper (luminal) zone of mid and distal colonic crypts, compared to untreated controls. However in rats treated with sinigrin there was also a significant increase in apoptotic cells in this region of the crypt. After 6 weeks, animals treated only with DMH had 25.3 \pm 5.4 ACF per colon; rats treated with $D M H$ followed by sinigrin had $15.0 \pm 2.7 \quad(p=0.003)$.

Conclusions: Consumption of sinigrin, which is a conjugated form of allyl isothiocyanate, suppressed the induction of ACF by DMH. This was coupled with evidence of increased apoptotic cell death in the DMH treated mucosa. In this experimental model, sinigrin may stimulate apoptosis after treatment with the carcinogen, thus favouring deletion of damaged cells from the intestinal mucosa, and reducing the induction of ACF.

\section{Liver (clinical) W20-W31}

W20

CHOLECYSTOKININ RELEASE BY FATTY ACID EVIDENCE FOR A THRESHOLD ACYL CHAIN LENGTH AND A CONCENTRATION EFFECT

JT McLaughlin K Daly, MG Luca', MN Jones\#, GJ Dockray*, DG Thompson. Dept of Medicine, Hope Hospital, Salford,
\#School of Biological Sciences, Manchester University, and *Physiology, Liverpool University, UK

Background: Cholecystokinin (CCK) is released from small intestinal endocrine cells, primarily by luminal fatty acids (FA) in humans. The exact FA acyl chain length required has not been determined, though we have recently shown equimolar $\mathrm{C} 18$ but not $\mathrm{C} 10$ to be effective. Acyl chain length affects solubility and physical state so it is important that each FA is delivered in a comparable physicochemical state such as an emulsion.

Aim: to determine (1) the acyl chain threshold for CCK release in vivo by saturated fatty acids of differing length and (2) the relationship between CCK secretion and FA concentration.

Methods: 6 healthy volunteers underwent 35 studies, receiving each test meal on a separate day. Vehicle solution (V) was $250 \mathrm{~m}$ phosphate buffered saline $(\mathrm{pH} 7.4,350 \mathrm{mOm} / \mathrm{kg})$ with $1.5 \% \mathrm{v} / \mathrm{v}$ Tween 80 to enable FA emulsification, and was used either alone as a control meal or with FA dispersed to produce $0.025,0.05$ or $0.10 \mathrm{M}$ emulsions. FA used were $\mathrm{C} 10, \mathrm{C} 11, \mathrm{Cl} 2$. Test meals were given by nasogastric tube after an overnight fast. Plasma samples were taken both fasted and 15 minutes after the test meal; radioimmunoassay for plasma CCK was performed.

Results: Fasting CCK was similar in each group. Initial studies showed CCK peak occurred at 15 minutes. Peak plasma CCK following V was $2.3 \pm 0.3 \mathrm{pM}$ (mean $+\mathrm{SEM}$ ). $\mathrm{C} 10$ or $\mathrm{C} 11$ did not increase CCK release: $0.05 \mathrm{M}$ C10: $2.0 \pm 0.4 ; 0.10 \mathrm{M} \mathrm{C10:2.7 \pm 0.4}$ $0.05 \mathrm{M} \mathrm{Cl1:} 2.5+0.8$. However plasma CCK was higher following all $\mathrm{C} 12$ meals: $0.025 \mathrm{M} 3.4 \pm 0.8 ; 0.05 \mathrm{M} 5.6 \pm 0.8(\mathrm{p}<0.01$ vs V); $0.10 \mathrm{M} 7.1+1.6(\mathrm{p}<0.02$ vs $\overline{\mathrm{V}})$ indicating a concentration-response relationship.

Conclusions: (1) a threshold acyl chain length of $\mathrm{C} 12$ exists for Conclusions: (1) a threshold acyl chain length of $\mathrm{Cl}$ exists for
$\mathrm{CCK}$ release and (2) CCK release by $\mathrm{C12}$ exhibits a concentration-response relationship.

Work supported by BBSRC.
DESCRIPTIVE EPIDEMIOLOGY OF PRIMARY BILIARY CIRRHOSIS (PBC): POSSIBLE LESSONS FOR FUTURE TRANSPLANTATION REQUIREMENTS IN BRITAIN IV Metcalf, OFW James, Department of Medicine,University of Newcastle upon Tyne, Newcastle NE2 4HAI

Recent epidemiological studies of PBC in the UK have suggested a prevalence of around 120 per million. However this work has involved case series, not cohorts of patients identified by consistent, exhaustive case finding methods and fulfilling a stringent case definition. We describe a study fulfilling the latter criteria, for 1st January 1987 to 31st December 1994, in a defined area in the NE of England (popln. c. 2.05 million).

Methods:All cases under care of gastroenterologists; RiS data; all death certificates (OPCS); all positive antimitochondrial antibody (AMA) from immunology labs (212 000 total screens examined). Case definition: all three of: AMA +ve $(\geq 1 / 40)$, cholestatic LFTs, compatible or diagnostic liver histology.

Results: 568 definite cases (M:F= 1:7.7). Point prevalence rose from 170.5 (1987) to 226.6 per million adults in 1994 follow up of 7.1 years. Mortality in the study period was 183 (32.2\%), of whom 116 died 'liver' deaths on review of notes $(63 \%)$. Only 59 were recorded as such on death certificates. Median time from diagnosis to death was 5.14 years. Mean age at death was significantly lower in the 'liver' death group 69.9 years v 72.4 years in 'non liver' death group $(p<0.05)$. More importantly there were 34 'liver' deaths in patients under 65 years, who would now receive liver transplants and 28 transplants, of whom 3 died. Thus the 'transplant load' of PBC in this population was up to 62 over 8 years or about 4 per million population per year.

Conclusions: i) OPCS reported liver related deaths underestimated true PBC 'liver' deaths by nearly 50\%; ii) if extrapolated throughout the UK these figures might suggest that the annual transplant requirement for PBC could be as high as 210 per year. (among women over 40 years 618.8 per million in 1994).Median 